\title{
Antimicrobial cytotoxicity and phytochemical activities of Spilanthes acmella
}

\author{
S. Ahmed ${ }^{a}$, A. Rahman ${ }^{b}$, T. Muslim ${ }^{b}$, M. H. Sohrab ${ }^{a}$, M. A. Akbor ${ }^{a}$, S. Siraj ${ }^{a}$ N. Sultana ${ }^{a}$ and M. A. Al-Mansur \\ a Analytical Research Division, BCSIR Laboratories Dhaka, Dhaka-1205 \\ ${ }^{b}$ Department of Chemistry, University of Dhaka, Dhaka-1000
}

\begin{abstract}
$\beta$-Sitosterone was isolated from the dichloromethane extract of the leaves of Spilanthes acmella. Stigmasterol was isolated from the petroleum and dichloromethane extract respectively. The structures of compounds were elucidated on the basis of spectral analysis as well as by comparison with available literature data. Pet-ether \& DCM extract and two column fractions of DCM and one pure compound were subjected to antimicrobial screening \& brine shrimp lethality. All of the fractions showed moderate to strong inhibitory activity to microbial growth. On the other hand, the pet ether extract and pure compound (stigmasterol) showed strongest cytotoxicity having $\mathrm{LC}_{50} 1.2 \mu \mathrm{g} / \mathrm{mL}$ and $2.02 \mu \mathrm{g} / \mathrm{mL}$ respectively.
\end{abstract}

Keywords: Antimicrobial activity; Bioassay; Extraction and isolation; Structural elucidation

\section{Introduction}

Spilanthes acmella (Bengali name- Banganda; FamilyCompositae) is a large glabrous or nearly so, which grows all over Bangladesh, India, Ceylon \& warm countries (Ghani, 2003, Kirtikar and Basu, 1980). The leaves and flower heads contain analgesic, antifungal, anthelminthic, and antibacterial agents, but some of the compounds are destroyed by desiccation or freezing. Spilanthes is also a potent sialogogue. The main active ingredient, spilanthol, has been reported poisonous to invertebrates (though harmless to warm-blooded creatures) and effective against blood parasites at even low concentration. The herb exhibits general immunomodulator properties when used internally, boosting production of leukocytes and antiviral interferon, as well as promoting phagocytosis. Although a large number of species of Spilanthes genus are being used ethnomedically for different kinds of diseases throughout the world, very little chemical or biological investigation has been done on Spilanthes acmella, but recently antibacterial activity of this species has been carried out. This investigation (Hoque et. al., 1986) reported that Spilanthes acmella has significant antibacterial activity against both Gram positive and Gram negative bacteria. Previous Phytochemical investigations resulted in the isolation of (E)-2-hexanol, 2-tridecanene germacrene, hexanol, $\beta$-caryophylline and (Z)-3-hexanol (Jirovets et. al., $2005)$, mycricyalc, pulmitic acid, stearic acid, $\beta$-amyrin acetate, $\beta$-sitosterol, $\beta$-amyrin, $\alpha$-amyrin, $\beta$-sitosterol $\mathrm{D}(+)$ glucoside and stigmasterol $\mathrm{D}(+)$ glucoside (Tiwari, et. al., 1990). Here, the preliminary antimicrobial and cytotoxicity activities of the organic extractives and the isolation of
$\beta$-Sitosterone \& Stigmasterol from the pet-ether \& dichloromethane extract were reported.

\section{Materials and methods}

Plant Material

The leaves of the plant Spilanthes acmella was collected from Curzon Hall area of Dhaka University campus to carry out the phytochemical study and a voucher specimen (No.32417) was deposited in the Department of Botany, University of Dhaka. The fresh leaves were taken into laboratory and cut into small pieces and were air dried. The leaves were finally dried at $38{ }^{\circ} \mathrm{C}$ in an oven and ground to powder by cyclotec grinding machine.

\section{General experimental procedure}

${ }^{1} \mathrm{H}(400 \mathrm{MHz})$ and ${ }^{13} \mathrm{C}(100.60 \mathrm{MHz}) \mathrm{NMR}$ spectra were recorded on a Bruker DPX- $400(400 \mathrm{MHz})$ instrument, with chemical shift data reported in ppm relative to the solvent used. General laboratory solvents were distilled from glass before use. Column chromatography (CC) was performed using silica gel $(0.063-0.2 \mathrm{~mm})$. Silica gel $60 \mathrm{~F}_{254}$ coated on aluminum plates for thin layer chromatography (TLC) was supplied by Merck.

\section{Extraction and Isolation}

The dried leaves powder $(500 \mathrm{gm})$ was extracted with petroleum ether $\left(60-80{ }^{\circ} \mathrm{C}\right)$ and dichloromethane $\left(\mathrm{CH}_{2} \mathrm{Cl}_{2}\right)$ in a 
soxhlet apparatus separately and successively. The two extracts were filtered individually and concentrated using a conventional distillation set and then a rotary evaporator (Buchi) under reduced pressure.

The concentrated pet-ether extracts $(10 \mathrm{gm})$ was fractionated by Vacuum Liquid Chromatography over silica gel (Kiesel gel 60, mesh 70-230), eluting with pet-ether-DCM $(0-100 \%)$ and then DCM-MeOH $(0-100 \%)$. The eluents were collected in an amount of about $20 \mathrm{~mL}$ in a series of test tubes. The eluted fractions were classified according to TLC into 9 fractions. Fraction-9 eluted from DCM-MeOH (985\%) afforded compound (1) Stigmasterol (4mg).

On the other hand, concentrated dichloromethane extract $(6.0 \mathrm{gm})$ was fractionated by Column Chromatography respectively over silica gel (Kiesel gel 60, mesh 70-230), eluting with $n$-hexane-DCM (75-90\%) and then DCM$\mathrm{MeOH}(100-50 \%)$. The eluents were collected in an amount of about $20 \mathrm{~mL}$ in a series of test tubes. The eluted fractions were classified according to TLC into 19 fractions. The fraction 1-3 (40mg) eluted from 25-35\% DCM in n-hexane. It was further subjected to Preparative thin layer chromatography, eluted with pet-ether-ethyl acetate $(80-20 \%)$ to yield compound which is similar to compound 1 .

The fraction 9-17 eluted from $n$-hexane-DCM (35-90\%) and then DCM-MeOH (100-10\%) combined and further subjected to silica gel column chromatography, elute with n-hexaneDCM (90-40\%) to yield compound (2) $\beta$-Sitosterone (3mg).

\section{Compound1 (Stigmasterol)}

${ }^{1} \mathrm{H}$ NMR (400 MHz,CDCI $): \delta 5.35(\mathrm{lH}, \mathrm{m}, \mathrm{H}-6), \delta 5.16$ $\left({ }^{1} \mathrm{H}, \mathrm{dd}, J=15.3,8.8 \mathrm{~Hz}, \mathrm{H}-22\right), \delta 5.03(\mathrm{lH}, \mathrm{dd}, J=15.3,8.6$ $\mathrm{Hz}, \mathrm{H}-23), \delta 3.51(\mathrm{lH}, \mathrm{m}, \mathrm{H}-3), \delta 0.85(1 \mathrm{H}, \mathrm{d}, J=7.6 \mathrm{~Hz}, \mathrm{H}-$ 26), $\delta 1.00(\mathrm{lH}, \mathrm{s}, \mathrm{H}-19)$.

${ }^{13}$ CNMR: $\delta 141.0$ ( C-5), $\delta 138.0$ ( C-22), $\delta 128.5$ ( C-23), 171.7 (C-6), $\delta 71.8$ (C-3), $\delta 56.9$ (C-14), $\delta 31.9$ (C-8), $\delta 21.3$ (C-26)

\section{Compound 2 ( $\beta$-Sitosterone)}

${ }^{1} \mathrm{H}$ NMR (400 MHz, CDCI3): $5.71(\mathrm{lH}, \mathrm{s}), 1.16(3 \mathrm{H}, \mathrm{s}, 19-$ $\left.\mathrm{H}_{3}\right), \delta 0.69\left(3 \mathrm{H}, \mathrm{s}, 18-\mathrm{H}_{3}\right), \delta 0.90\left(3 \mathrm{H}, \mathrm{d}, J=6.4,26-\mathrm{H}_{3}\right)$, $0.84(3 \mathrm{H}, \mathrm{d}, J=7.4 \mathrm{H}-)$.

\section{Antimicrobial Screening}

In the present study, all extracts and pure compounds were tested for antimicrobial activity by the disc diffusion methods (Bauer et. al., 1966). Laboratory isolates of 13 bacterial species which include five Gram-positive and eight Gramnegative bacterial strains and three fungus Candida albicans,
Aspergillus niger, Sacharomyces cerevacae were taken for the test. The bacteria were Bacillus cereus, Bacillus megaterium, Bacillus subtilis, Staphylococcus aureus, Sarcina lutea, Escherichia coli, Pseudomonas aeruginosa, Salmonella paratyphi, Salmonella typhi, Shigella boydii, Shigella dysenteriae, Vibrio mimicus, and Vibrio parahemolyticus. Each organism was maintained on nutrient agar slant. The samples were dissolved separately in chloroform and applied to sterile filter paper disc at a concentration of $500 \mu \mathrm{g} / \mathrm{disc}$. Kanamycin disc $(30 \mu \mathrm{g} / \mathrm{disc})$ was used at standard in each study. The sample disc, standard disc and control discs were placed gently on the previously marked zones in the agar plates pre-inoculated with test bacteria. The plates were then kept in a refrigerator at $4{ }^{\circ} \mathrm{C}$ for about 24 hours upside down to allow sufficient diffusion of the materials from discs to the surrounding agar medium. The plates were then inverted and kept in an incubator at $37{ }^{\circ} \mathrm{C}$ for 24 hours. The antimicrobial potency of the test agents were measured by their activity to prevent the growth of the microorganisms surrounding the discs which gives clear zone of inhibition. After incubation, the antimicrobial activities of the samples were determined by measuring the diameter of the zones of inhibition in millimeter with a transparent scale.

DMSO solutions of the leaves extracts were assayed for cytotoxicity against Artemia sarina in a 1-day in vivo assay the experimental details of which could be found elsewhere (Meyer et. al., 1982). For the experiment $4 \mathrm{mg}$ of each of the fractions was dissolved in DMSO. Solutions of varying concentrations such as $400,200,100,50,25,12.50,6.25,3.125$, $1.563,0.781 \mathrm{~g} / \mathrm{mL}$ were obtained by serial dilution technique. The median lethal concentration LC5s of the test samples after $24 \mathrm{hrs}$ was obtained by a plot of percentage of the shrimps killed against the logarithm of the sample concentration. Here vincristine sulphate was used as a standard.

\section{Results and discussion}

Compound 1 were isolated from pet-ether extract and Compound 2 was isolated from dichloromethane extract of the leaves of Spilanthes acmella. The structures of the isolated known compound were identified by comparison of their physical and spectral data with literature as stigmasterol (Deyuxie et. al., 2000, Sadia et. al., 2008) and $\beta$-Sitosterone (Sadia, 2006).

Compound 1 was white crystalline compound, m.p. 148$150{ }^{\circ} \mathrm{C}$. It showed purple color on TLC when visualized with anisaldehyde-sulphuric acid spray reagent. The IR spectrum (liquid film) showed hydroxyl absorption bands at 3450 $\mathrm{cm}^{-1}(\mathrm{OH})$ and other bands appeared at $2920 \mathrm{~cm}^{-1}(\mathrm{CH})$, $1655 \mathrm{~cm}^{-1}(\mathrm{C}=\mathrm{C})$. The ${ }^{1} \mathrm{H}$ NMR spectrum showed two ${ }^{1} \mathrm{H}$ 

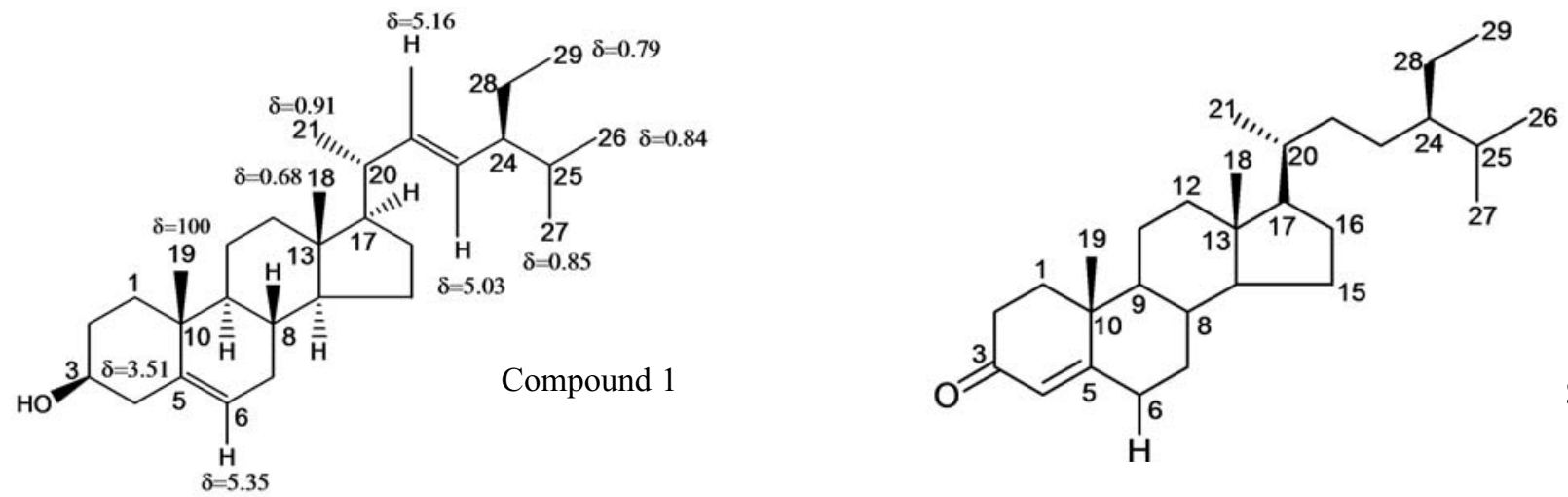

Fig. 1. The structures of isolated compounds from $S$. acmella

multiplets at $\delta 3.51$ and $\delta 5.35$ typical for $\mathrm{H}-3$ and $\mathrm{H}-6$ of a steroidal nucleus. The olefinic protons $\mathrm{H}-22$ and $\mathrm{H}-23$ appeared as characteristics downfield signal at $\delta 5.16$ and $\delta$ 5.03 respectively in the ${ }^{1} \mathrm{H}$ NMR spectrum. This two signal was observed as double doublet $(J=15.3$ and $8.8 \mathrm{~Hz}$ and $J$ $=15.3$ and $8.6 \mathrm{~Hz}$ ) which indicated coupling with the neighboring olefinic and methine protons. The ${ }^{1} \mathrm{H}$ NMR spectrum displayed two three-proton singlets at $\delta 1.0$ and 0.68 assignable to two tertiary methyl groups at $\mathrm{C}-19$ and $\mathrm{C}-18$ respectively. In addition, two doublets at $\delta 0.85(J=7.6 \mathrm{~Hz})$ and $0.84(J=6.9 \mathrm{~Hz})$ integrating for three protons to the two methyl group at C-26 and C-27. Another three-proton doublet at $\delta 0.91(J=6.4 \mathrm{~Hz})$ could be attributed to the methyl group at C-21. These spectral features are characteristics of a steroidal carbon skeleton of stigmasterol and were identi- cal to that reported data for stigmasterol (Sadia et. al., 2008). Therefore, the structure of the compound 1 was established as stigmasterol.

Compound 2 was isolated as white crystalline powdered, m.p $120-122^{\circ} \mathrm{C}$. The IR spectrum showed absorption bands at $3450,2920,2850,1655,1455,1365,1040 \mathrm{~cm}^{-1}$. The ${ }^{1} \mathrm{H}$ spectrum showed one one-proton singlet at $\delta$ 5.71.This significant downfield signal of the olefinic proton at $\delta 5.71$ typical for $\mathrm{H}-4$ of a steroidal nucleus containing a ketone group at $\mathrm{C}-3$ position. It also displayed two three-proton singlets at 1.16 and 0.69 assignable for the methyl group at C-19 and C-18 respectively. In addition two three-proton doublets at $0.84(J=7.6 \mathrm{~Hz})$ and $0.80(J=7.2 \mathrm{~Hz})$ could be ascribed to the two methyl groups at $\mathrm{C}-26$ andC-27 respectively and

Table I. Antimicrobial activity of extracts and isolated compounds (1-2) from $S$. acmella

\begin{tabular}{|c|c|c|c|c|c|}
\hline Test bacteria \& fungus & $\begin{array}{c}\text { Pet-ether extract } \\
(500 \mu \mathrm{g} / \text { disc })\end{array}$ & $\begin{array}{l}\text { DCM extract } \\
(500 \mu \mathrm{g} / \text { disc })\end{array}$ & $\begin{array}{l}\text { Compound } 1 \\
(300 \mu \mathrm{g} / \mathrm{disc})\end{array}$ & $\begin{array}{l}\text { Compound } 2 \\
(300 \mu \mathrm{g} / \mathrm{disc})\end{array}$ & $\begin{array}{l}\text { Amoxicillin } \\
(30 \mu \mathrm{g} / \mathrm{disc})\end{array}$ \\
\hline \multicolumn{6}{|l|}{ Gram-positive bacteria } \\
\hline Bacillus cereus & 12 & NA & NA & NA & NA \\
\hline Bacillus subtilis, & NA & NA & 8 & 8 & NA \\
\hline Bacillus megaterium & 12 & NA & NA & NA & 33 \\
\hline Sarcina lutea & 10 & 7 & 8 & NA & 10 \\
\hline Stapylococcus aureus & 12 & 8 & 7 & 7 & 28 \\
\hline \multicolumn{6}{|l|}{ Gram-Negative bacteria } \\
\hline Salmonella typhi & 10 & NA & 7 & 8 & NA \\
\hline Salmonella paratyphi & 12 & NA & 8 & NA & 15 \\
\hline Pseudomonas aeruginosa & 8 & 7 & 7 & 8 & 10 \\
\hline Shigella boydii & 10 & 7 & 8 & NA & NA \\
\hline Escherichia coli & 6 & NA & NA & NA & 20 \\
\hline Vibrio parahemolyticus & NA & 7 & NA & NA & 12 \\
\hline Shigella dysenteriae & 10 & 6 & 6 & 6 & 20 \\
\hline Vibrio mimicus & 10 & NA & 7 & NA & 30 \\
\hline \multicolumn{6}{|l|}{ Fungus } \\
\hline Candida albicans & 10 & 8 & 7 & NA & 12 \\
\hline Aspergillus niger & NA & 7 & 8 & 7 & 10 \\
\hline Sacharomvces cerevacae & 10 & 7 & 7 & 7 & NA \\
\hline
\end{tabular}

$\mathrm{NA}=$ No activity 
another three-proton doublet at $\delta 0.90(J=6.4 \mathrm{~Hz})$ could be attributable for $\mathrm{C}-21$. These ${ }^{1} \mathrm{H}$ NMR spectral features are characteristics of steroidal carbon skeleton of Sitosterone. On this basis and compared with published data (Sadia, 2006) the compound 2 was identified as $\beta$-Sitosterone.

The bacterial and fungal strains used for the experiment were collected as pure cultures from the Institute of Nutrition and Food Science (INFS), University of Dhaka. The anti-bacterial activities of pet-ether, dichloromethane extracts, compound 1 and Compound 2 were compared with standard Amoxicillin and the results are reported in Table I. The zone of inhibition produced by the pet-ether, dichloromethane extract, Compound 1 and Compound 2 was found to be 9-12 $\mathrm{mm}, 6-8 \mathrm{~mm}, 7-8 \mathrm{~mm}$ and $8-9 \mathrm{~mm}$ respectively at a concentration of $500 \mathrm{~g} /$ disc The results showed that the pet-ether extract had more inhibitory effect than dichloromethane extracts. In the antifungal assay, the title plants have displayed high antifungal activities. Pet-ether extract showed the highest activities, inhibiting the growth of $C$. albicans and $S$. cerevacae up to $10 \mathrm{~mm}$.

Following the procedure of Meyer (Meyer et. al., 1982), the lethality of the pet ether (PE), dichloromethane (DCM) extract and compound to brine shrimp was determined on A. salina. Table II shows the results of the brine shrimp lethality testing after 24 hours of exposure to the samples and the positive control, vincristine sulphate. The $\mathrm{LC}_{50}$ obtained from the best-fit line slope were found to be 1.2, 1.1, 2.02 $\mathrm{g} / \mathrm{mL}$ for pet ether, dichloromethane and pure compound, respectively. In comparison with the positive control (vincristine sulphate), the cytotoxicity exhibited by compound 1 shows the highest activity and the pet ether and dichloromethane extract was significant. Comparison with positive control vincristine signifies that cytotoxicity exhibited by the pure compound as well as the crude extract is promising and they might have antitumour or pesticidal compounds. However, this can not be confirmed without further higher and specific tests.

Table II. $\mathrm{LC}_{50}$ data of test samples of Spilanthes acmella

\begin{tabular}{lc}
\hline Sample & $\mathrm{LC}_{50}$ \\
\hline VS & 0.33 \\
PE & 1.2 \\
DCM & 1.1 \\
Compound 1 & 2.02 \\
\hline
\end{tabular}

VS: vincristine sulphate (Std.), PE: pet-ether extract, DCM: dichloromethane extract,

The results of antimicrobial and cytotoxicity screening were found to be consistent with the folk uses of Spilanthes acmellas.

\section{Conclusion}

The crude pet-ether and dichloromethane extracts of $S$. acmellas showed significant inhibition activity (Table I) against tested bacteria and fungus. The pet-ether and dichloromethane extract was fractionated and yielded two compounds (1-2). The antimicrobial activities of compounds 1 and 2 were moderate against Bacillus subtili, Stapylococcus aureus and Salmonella typhi (Table I), while only compound 1 showed significant antifugal activity against the three fungi. The present results may provide some explanation for synergetic effect of crude extracts as well as the medicinal uses of this plant.

\section{References}

Bauer AW, Kirby WMM, Sherries JC and Truck M (1966), Antibiotic susceptibility testing by standard single disc diffusion method. Am. J. Clini. Pathol. 45: 426-493.

Deyuxie Lianhui, Hechun and Guofen Li. (2000), Plant Tissue and Organ Culture, 63(2): 161-166.

Ghani A (2003), Medicinal Plants of Bangladesh: Chemical Constituents and Uses. 2nd edition (Asiatic Society of Bangladesh), p p. 345.

Hoque, MM, MA Hassan \& MR Khan (1986), Studies on the antibacterial activity of plants available in Bangladesh. Asiatic Soc. Bangladesh (Sc), 12(1\&12): 77-82.

Jirovets LB, Gerhard W and Shafi T (2005), Essential oil analysis of S. acmella from fresh plants, Journal of Essential oil Research, 17 (4): 429-431.

Kirtikar KR and Bas BD (1980), Indian Medicinal plants. 2nd edition (Vol 1) B. singh and M.P Singh publishers, India, pp 345.

Meyer BN, Ferringni NR, Puam JE, Lacobsen LB, Nichols DE and McLaughlin JL (1982), Brine shrimp: a convenient general bioassay for active constituents. Planta Medica 45: Pp.31-32.

Sadia (2006), Phytochemical studies on polgonum stagninum, M.Pharm Thesis, pp 139, University of Dhaka, Dhaka -1000, Bangladesh.

Sadia A, Chowdhury M, Hossain S, Bidyut K, Datta CM Hasan (2008), Chemical and Antioxidant Studies of Citrus macroptera. Bangladesh J. Sci. Ind. Res. 43(4): 449-454.

Tiwari HP and Kakkar A (1990), J. Indian Chem. Soc., 67(9): 784-5.

Received: 27 January 2011; Revised: 14 February 2012; Accepted: 26 April 2012. 